\title{
Insurance Contract Law Reform in England and Scotland - An Update
}

\section{David Hertzell}

Published online: 22 August 2008

(C) ERA 2008

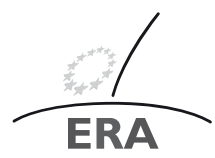

EUROPÄ|ISCHE RECHTSAKADEMIE ACADEMY OF EUROPEAN LAW ACADEMIE DE DROIT EUROPEEN ACADEMTE DE DROHT EUROPEEN TRIER - TREVES - TREVIRI

\section{Introduction}

The purpose of this article is to provide an overview of the progress of the English and Scottish Law Commissions' project to reform insurance contract law and the response of the insurance market (to include policyholders, brokers, academics, lawyers, insurers and reinsurers) to the Commissions' proposals. This article is not intended to provide the reader with a detailed discussion of the Commissions' proposals for reform. These details may be found through the Commissions' web sites at www.lawcom.gov.uk and www.scotlaw.go.uk where the Commissions have published a Consultation Paper, a Summary of Proposals and a Summary of Responses in respect of their consumer proposals. A summary in respect of business proposals will be published later this year.

\section{Project history}

Following the publication of Scoping and Issue Papers the first Consultation Paper in this project was published on 17th July 2007 with a consultation period closing on 16th November 2007. The consultation paper (“CP1”) covered three key topics:

David Hertzell $(\square)$

Law Commission, Conquest House

37-38 John Street, Theobalds Road, London WC1N 2BQ, United Kingdom e-mail: David.Hertzell@LAWCOMMISSION.GSI.GOV.UK

This paper is the written version of the presentation given by the author at the conference European Insurance Contract Law and the Common Frame of Reference (CFR), organised by ERA and the Joint Network on European Private Law in Trier on 21-22 January 2008. 
a) Misrepresentation and non-disclosure by the insured;

b) The role of intermediaries in this context;

c) Insurance Warranties.

CP1 also dealt with some specific issues relating to group and life insurance.

The law governing the topics covered by CP1 derives primarily from the Marine Insurance Act 1906 ("MIA"). This Act reflects the time at which it was drafted and the specialist market it was drafted for. It is heavily biased in favour of insurers. Purchasers of insurance whether businesses or consumers are obliged to disclose to insurers any information which would affect the judgement of a "prudent underwriter" when considering the risk. If such information is not disclosed or is misrepresented then the insurer is entitled to avoid the policy ab initio and to refuse to pay the claim. The law is equally strict in relation to warranties. Breach of a warranty will discharge the insurance contract. The claim will not be paid. There is no requirement to show any link between the breach of warranty and the loss that occurred. There is no need for the insurer to show that they were induced by the warranty into accepting the risk.

For consumers the MIA is now effectively by-passed by Industry Codes of Practice and guidance notes, the Financial Ombudsman Service ("FOS") and Financial Services Authority ("FSA") regulation. The MIA remains the governing law for business insurance including small and medium enterprises to the extent that these fall outside the FOS limits and FSA rules.

CP1 defined and adopted much from insurance industry guidelines, codes of practice and FOS decisions to produce proposals for a more evenly balanced law for consumer insurance. The Commissions propose that consumers should not have an obligation to volunteer information. However consumers must answer the questions asked by insurers honestly and reasonably. If they fail to do so then insurers will only be obliged to pay those claims where the consumer's misrepresentation was reasonable but will be entitled to avoid policies where the consumer has been dishonest or reckless. If the consumer has been negligent then the outcome will depend on what would have happened if the correct information had been provided. For example the insurer may have imposed a term excluding the loss in which case the claim may not be paid (but the policy will continue) or it may have charged more premium in which case the consumer will receive only a proportional payment. Warranties of past and present facts for consumers would be treated as representations. Consumers could still give warranties for future actions but for these to be effective there would have to be a link between the warranty given and the loss that occurred.

There are similar proposals for business insurance although some differences are retained. For example whereas consumers are only required to answer the questions they are asked in a proposal form a residual duty of disclosure is retained for businesses. Businesses can give warranties of past or present facts but as with consumers there has to be a causal link between the loss and the warranty for it to be effective. These differences reflect the fact that businesses differ greatly in size and type, cover a broad spread of activities, are often advised and can have a level of sophistication not available to consumers.

The consumer proposals are mandatory but the business proposals are to be a default regime as is currently the case with the MIA. However some controls are placed 
on the ability to contract out of the default regime where the policyholder is likely to be a SME and the policy is written on a standard non negotiated basis. The Commissions are aware that the vast majority of businesses in the UK are SME's.

The Commissions also considered the responsibility of intermediaries for the transfer of information from policyholder to insurer at placement of the insurance contract. The Commissions decided to retain the existing legal principle that liability for failure to transfer information accurately would depend on whether the intermediary was the agent of the insurer or the policyholder. Should the intermediary make an error which entitled the insurer to avoid or limit the payment of a claim then the consumer would have to seek a remedy against the intermediary if the intermediary were their agent. If the intermediary were the insurer's agent then the claim would be paid and the insurer would have a remedy against the intermediary. The Commissions proposed that the test to decide the role of the intermediary would be based on whether the intermediary carried out a "fair market analysis". If it did then the intermediary would be the agent of the insured and vice versa.

Following the publication of $\mathrm{CP} 1$ the Commission teams undertook an active programme of engagement with the insurance market to encourage a wide response.

In the event 105 responses were received to CP1. Although consultees were provided with the option of a "tick box" response form many chose to respond in considerable depth. The Commissions have succeeded in their aim of provoking a comprehensive response from the wider insurance market and one that also reflects the views of individual participants.

The breakdown of responses is as follows:

- 25 lawyers/legal associations

- 39 insurers/insurance associations

- 13 brokers/brokers association

- 7 consumer/consumer associations

- 8 business buyers/buyers association

- 5 academics

- 8 others (e.g. regulators/service providers).

The associations tend to have wide membership. The responses therefore represent a very broad market participation in the consultation process.

\section{The responses}

\subsection{Structure of the reforms}

The majority of the consultees support:

- the need for reform particularly for consumers

- that all types of insurance should be included

- a mandatory regime for consumer insurance

- that the regime for business insurance should be a default regime. A freedom of contract option should be preserved

- that there should not be a separate regime for small businesses. 


\subsection{Non-Disclosure/misrepresentation}

The majority of consultees support:

- the abolition of the duty of disclosure for consumers.

- the retention of a duty of disclosure for business insureds.

- a hierarchy of remedies (pay the claim/a proportional payment/avoid the policy) matched against policyholder actions (reasonable error/negligent error/dishonest misrepresentation). Support for this approach was however less strong for business insurance than for consumer insurance.

- the proposal that the test of "reasonable insured" should replace the existing test of "prudent underwriter" as the perspective from which to judge whether a misrepresentation was material. Again support for this approach was less strong for business insurance than for consumer insurance.

\subsection{Warranties}

The majority of consultees support:

- the abolition of "basis of contract" clauses by which representations made by the policyholder in a proposal form are treated as warranties breach of which allows the insurer to avoid the claim and discharge the contract.

- that warranties of a present or past fact by a consumer should instead be treated as a representation.

- that warranties of present and past fact should be preserved for business policyholders.

- that future warranties (i. e. promises to undertake an action) should be preserved for both business and consumer policyholders.

- a requirement that in order for the insurer to have a remedy there needs to be a causal contribution between the breach of warranty and the circumstances of the loss.

\subsection{Points for consideration}

Although there is an inevitable diversity of views amongst consultees on many of the proposals in CP1 the following are proposals where there is either opposition or a considerable number of alternative suggestions.

- For business insureds CP1 proposed that if the insurance was written on "standard terms of business" any terms which purported to be less favourable to the insured than the default regime would be invalid if such terms failed to meet the "reasonable expectations" of the policyholder. The intention was to protect small businesses buying insurance through contracts that were not negotiated. Many consultees expressed concern as how "standard terms" would be defined in practice. There was also widespread concern or misunderstanding as to what was intended by a "reasonable expectations" test.

- CP1 proposed that an intermediary would be the agent of the insurer unless the intermediary undertook a "fair market analysis" as defined by the Intermediaries Directive. The majority of consultees considered that this is an inadequate test to apply. Consultees felt that there is a very broad spread of different business 
relationships amongst brokers, policyholders and insurers and that the proposal in CP1 is too simplistic.

- CP1 proposed that a policyholder's signature should not be conclusive evidence of the accuracy of information provided in the proposal form. Although there was some support for this suggestion amongst consumer groups the majority of consultees opposed it.

- CP1 proposed in the context of life insurance that there should be a five-year non-contestability period after which insurers would not be able to rely upon a negligent misrepresentation. Although some consultees supported this suggestion on the basis that it would increase market confidence the majority of life insurers opposed it.

\subsection{Business Insurance}

As noted above there is a very much broader range of responses to the proposals in CP1 relating to business insurance. Responses are not divided on "party lines" amongst buyers, brokers and insurers. Responses are however divided between parties who are involved with volume insurance whether the policyholders are consumers or business buyers and those who are involved with more specialised and often international business. This is perhaps not unexpected. It reflects the fact that in the specialist market place policyholders are likely to be more sophisticated and are also likely to be advised by sophisticated brokers. It also reflects the underlying business model.

In the volume market place any increased costs imposed by the proposals in CP1 will be shared across a wide pool of insureds. Members of the pool are in effect purchasing additional insurance against their own error. Members of the pool are generally all equally likely to commit such errors. That is more difficult to justify where the pool is smaller and more specialised. Why should sophisticated businesses in a small risk pool pay for the errors reasonable, negligent or otherwise of their direct competitors? The challenge this imposes for the Commissions is that despite the differences between the responses from the specialist and volume market places the majority of consultees do not wish to see a small business regime or specialist market areas such as marine, aviation, transport and reinsurance excluded from the proposals.

\section{Consultation Paper 2}

Based on responses to the original Scoping Paper issued in 2006 the Commissions propose to publish a second Consultation Paper ("CP2") in 2009. CP2 will cover insurable interest, post contractual duties of good faith, fraud and damages for late payment of claims. There are also one or two miscellaneous items relating to redundant legislation or unused provisions in the MIA which could be included in this paper.

An Issues Paper on insurable interest was published in January 2008. A copy and Summary are available through the Commissions' web sites. The law currently requires the policyholder to have "an interest", which is normally a financial concern, in the subject matter of the insurance in order to bring a claim. Where the insurance is for a fixed sum payable on the occurrence of a specified event (for example life 
insurance) the Life Assurance Act 1774 provides a narrow range of categories where insurable interest is deemed to exist. In either case if the policyholder has no such interest then the contract is not insurance but a wager.

The Commissions do not expect their suggestions for general insurance (e.g. property, liability insurance etc) to be controversial as the Issues Paper agrees with the current legal position. In order to bring a valid claim the policyholder must have suffered a loss and therefore have had an "interest" at least at the date of loss. There is more discussion regarding life insurance where the Commissions have suggested an alternative of extending the categories of those covered by "natural affection" as the basis for establishing insurable interest in a life or abandoning the requirement for insurable interest altogether. The market's response will be analysed at the end of the consultation period. There are no particular policy grounds for preferring one course of action to the other although the Commissions have tentatively recommended an evolutionary rather than revolutionary approach.

The remaining areas of $\mathrm{CP} 2$ relate to the claims process and are likely to prove more controversial. There are in addition some fundamental differences between English and Scots Law. As before the Commissions will attempt to ensure the active participation of the wider insurance market in the consultation and discussion process. The Commissions believe that despite the time and effort involved such participation will improve the final legislation. Subject to any unforeseen problems the Commissions anticipate completing this project in 2011. 